\title{
Exploring Determinants of Adoption and Higher Utilisation for E-Government: A Study from Business Sector Perspective in Saudi Arabia
}

\author{
Saleh Alghamdi \\ University of Sussex, \\ Informatics Department \\ Brighton, UK \\ Email: sa434@sussex.ac.uk
}

\author{
Natalia Beloff \\ University of Sussex, \\ Informatics Department, \\ Brighton, UK \\ Email: N.Beloff@sussex.ac.uk
}

\begin{abstract}
Providing e-Government services to business sector is a fundamental mission of governmental agencies in Saudi Arabia. The adoption of e-Government systems is less than satisfactory in many countries, particularly in developing countries.One pertinent, unanswered question is what are the key factors that influence the adoption and utilisation level of users from business sector. This paper utilised e-Government Adoption and Utilisation Model (EGAUM) proposed in our previous work in order to analyse determinants of higher level of e-Government adoption and usage. The study involved 48 participating business entities from two major cities in Saudi Arabia, Riyadh and Jeddah. The descriptive analysis is presented in this paper and the results indicated that all the proposed factors have degree of influence on the adoption and utilisation level. Perceived Benefits, Functional Quality of Service, Previous Experience, Perceived Simplicity, Accessibility and Regulations \& Policies factors were found to be the significant factors that are most likely to influence the adoption and usage level of users from business sector.
\end{abstract}

\section{INTRODUCTION}

$\mathbf{E}$ -GOVERNMENT refers to the utilisation of various Information and Communication Technologies (ICTs) for facilitating communication between the government and the stakeholders; citizens, businesses and governmental agencies, providing effective, efficient and integrated e-Services that enhance the interaction between the government and the stakeholders through multiple and flexible channels that lead to an increased engagement. Adoption and utilization level is fundamental in terms of measuring the successfulness of the implemented e-Government systems. As governments develop e-Government systems to provide e-Services to stakeholders, the adoption and usage level is still low especially in developing countries [1][2][3]. Successful implementation of ICTs in government units and satisfactory usage level by all government stakeholders are the main goals of e-Government. Thus, analysing the significant factors that influence the adoption and utilisation of e-Government is becoming a necessity.

One of the main targeted stakeholders when providing e-Government services is business sector. The business sector, or what so called private sector in Saudi Arabia, is growing considerably in the recent years. The growth rate of the private sector is the highest between the three main sectors in Saudi Arabia, namely, governmental sector, private sector and oil sector [4]. Therefore, facilitating the communication and interaction between government agencies and business sector (business firms) is very important especially in the current advanced IT era. Many online e-Services have been provided to the private sector in the recent years in Saudi Arabia and there are more e-Services under development. Besides the need to increase the adoption and utilization level of the implemented e-Government systems, it is also crucial to understand the factors that can influence the adoption and usage of the new e-Services. The analysis of such factors will bring e-Government service provided to business sector to a more successful level and also will draw the path for developing new e-Government services.

In order to explore the determinant factors of high adoption and usage level of e-Government, we need to utilize a comprehensive framework. Thus, this paper used E-Government Adoption and Utilisation Model (EGAUM) see [5]. This model was developed based on critical evaluation of several common models and theories related to technology acceptance and usage including TAM and UTAUT, in conjunction with analysis of technology acceptance literature [5]. The rest of this paper will be divided as follows; the second section will explain the research methodology and the third section will present and discuss the research findings. The final section will provide a conclusion and our planned future work as this study is a part of our on-going research.

\section{Research Methodology}

The study surveyed 53 business entities from different cities in Saudi Arabia, namely, Riyadh and Jeddah. Most of them were leader and large companies. Several medium and small business entities have also been involved in this study sample. The data has been collected in the period between August and October 2014. The business activities 
of the participating companies were different in order to provide more comprehensive results. The sample included both business owners and employees who work in business firms and deal with government agencies with regard to their companies' transactions.

A 99-item questionnaire was distributed to the participants to respond to. The questionnaire comprised different forms of questions. Although the questionnaire was relatively long, it collected fundamental data that led to efficient and sufficient analysis. Moreover, a semi-structure short interview has been conducted with number of participants and it was optional. The questionnaire was distributed in person for several reasons including 1) ensuring high response rate, 2) clarifying questions when participant need, 3) conducting the short interview after completing the questionnaire. Users from business sector are usually busy. Therefore, meeting them in person at appropriate time to collect data is a useful method. The data has been collected from different cities in Saudi Arabia. Although this way consumed effort, cost and time, it enabled us to obtain more comprehensive and useful data.

Since the factors in the research model (EGAUM) are abstract [5], number of items was developed for each factor to measure its influence on the adoption of e-Government. Raubenheimer stated that number of items per factor is crucial specifically for scales with one factor which requires at least four items to be identified. However, most of the scales measure more than one factor. Scales that measure more than one factor, like this research scale, can be identified with as little as two items [6]. Table 1 shows the number of items for each factor in the scale developed for this study. The table exclude the personal factors since they are not measurable factors.

This research aims to study the influential factors of adopting and utilizing e-Government in the context of Saudi Arabia. Therefore, Saudi nationality was the targeted sample since the study involved some factors that aimed to be studied in the Saudi context such as socio-cultural, perceived trust and previous experience. The exclusion of non-Saudi nationalities is associated with the research goals of conducting a cross-sectional study of Saudi society. Moreover, the research instrument was designed to collect data relate to the Saudi context such as opinions about the available payment methods in Saudi Arabia, the Saudi post mail services and the influence of WASTA, which refers to the use of interpersonal relationships in transactions processing, on the adoption of e-Government. Moreover, incomplete questionnaires were also excluded since all the questionnaires' items need to be answered as they represent the research model constructs. Therefore, the total valid responses were from 48 business entities.

\section{A. Reliability and validity}

Blunch stated that a research instrument is evaluated by its reliability. The reliability of a measuring instrument means its ability to provide identical results if it is repeated under identical conditions [7]. It concerns with a question "can we get the same results if we repeat the measurement test?". There are many different methods to determine the reliability of an instrument including Test-retest method, Split-Half method and Internal Consistency method. There were difficulties of using some of these methods in this research context. For example, repeating the test in different times with the same participants as in Test-retest method was difficult since the data collection phase in this study aimed to be conducted in different country, Saudi Arabia, whereas the researchers are in the United Kingdom. Moreover, Split-half method is appropriate for the long questionnaires that measure or test one construct and it is not suitable for instruments that measure several constructs as the current study [8]. Thus, this study used the internal consistency method to test the reliability with the use of Cronbach's Alpha., see Table 1.

Internal consistency method determines how the items in a test relate to the other items. It is basically used to assess a survey items with a single construct to discover the consistency degree of the items that measure that construct. Cronbach's Alpha is the most common coefficient that can be calculated to evaluate the internal consistency of a test. It is applied to responses that have more than two options [9]. Therefore, it is applicable to this research instrument. Cronbach's Alpha reliability coefficient could range between 0 and 1 with value closer to 1 is considered to be high level of reliability. Acceptable level of reliability depends on the research purpose. The reliability of an instrument developed for research purposes is acceptable at 0.6 where in diagnostic research that the instrument is developed to make decision on individuals, such as psychological tests, need to be much higher [10].

In terms of validity, Bhattacharyya defined it as "the degree to which a test measures what it intends to measure" [11]. Validity of an instrument does not mean that the instrument is either valid or not but it is a matter of degree. The greater

TABLE 1: Internal consistency of the study instrument

\begin{tabular}{lcc}
\hline Measured variable & \# of items & Cronbach's $\alpha$ \\
\hline Perceived Benefits (PB) & 7 items & .825 \\
Socio-Cultural (SC) & 5 items & .686 \\
Awareness (AW) & 9 items & .822 \\
Functional Quality of Services (FQS) & 10 items & .800 \\
Previous Experience (PE) & 3 items & .601 \\
Perceived Simplicity (PS) & 6 items & .638 \\
Technical Quality of Service (TQS) & 5 items & .624 \\
Accessibility (ACC) & 4 items & .619 \\
Perceived Trust (PT) & 9 items & .792 \\
Regulations and Policies (RP) & 4 items & .899 \\
Intention to use e-Government (ITU) & 2 items & .659 \\
Perceived e-Readiness of e-Government (PER) & 2 items & .667 \\
\hline
\end{tabular}


the evidence that an instrument produces valid results the greater the likelihood that we will get information that we need [12]. Validity cannot be calculated or measured directly, it is judged by the existing evidence [13]. There are several methods to determine or assess the validity of a research instrument and the most dominant ones include face validity, content validity, criterion validity and construct validity. This study utilised face validity and content validity methods to evaluate its validity degree.

Face Validity method provides useful information about the measure instrument and determines to what extent the instrument meets the intended purpose [12]. Test in which its purpose is clear, even for simple persons who have elementary knowledge, is judged to have high face validity. Where on the other hand, test in which its purpose is unclear would be judged to have low face validity [14]. Most of the items developed in this study were accurately face validated during the pilot study phase by the participants in accordance to the model factors' purposes, whereas some of them were not validated due to lack of understanding them clearly. Invalid items were either reworded if they were reported as unclear or deleted if they were reported as irrelevant. Furthermore, 5 academic members who are experts in interactive systems field have also reviewed the research instrument to have high content validity. Thus, it has been reviewed, tested and revised several times in order to have high validity.

\section{RESEARCH FINDINGS AND DISCUSSION}

This section provides an overview of the demographic characteristics of the respondents including age groups, education level, income, the use of the Internet and the use of eGovernment systems. This is followed by a descriptive analysis for each factor proposed in EGAUM in order to explain their influence on the participants' adoption and utilisation of e-Government services provided to business sector.

\section{A. Respondents' demographic data}

This section analyses demographic data obtained from the respondents (see Table 2). As per the questionnaire results, the average age group was ranging between 31 and 45 with males accounting for $89.5 \%$ of the participants and $10.4 \%$ were female. It is clear that the percentage of male participants was more than female participants. These percentages were expected for several reasons. Most of the employees who work in business sector (private sector) and use e-Government services in their jobs' activities are male employees. This is mainly because the jobs that involve dealing with government agencies to perform governmental transactions were almost exclusive to men before implementing e-Government in Saudi Arabia, therefore, they dominate these kinds of jobs due to their experience of dealing with the government services. Furthermore, it is difficult to collect data personally from female in Saudi Arabia, either business owners or employees, due to religious and cultural reasons.
TABLE 2: Demographic data

\begin{tabular}{|c|c|}
\hline Variables & $\%$ \\
\hline \multicolumn{2}{|l|}{ Participants gender } \\
\hline Male & 89.6 \\
\hline Female & 10.4 \\
\hline \multicolumn{2}{|l|}{ Participants age in years } \\
\hline $18-30$ & 20.8 \\
\hline $31-45$ & 64.6 \\
\hline $46-60$ & 12.5 \\
\hline Over 60 & 2.1 \\
\hline \multicolumn{2}{|l|}{ Participants education level } \\
\hline Secondary school or less & 29.2 \\
\hline Diploma & 20.8 \\
\hline Bachelor degree & 41.7 \\
\hline Master & 8.3 \\
\hline \multicolumn{2}{|l|}{ Proficiency of using computer } \\
\hline Average & 8.3 \\
\hline Good & 41.7 \\
\hline Excellent & 50 \\
\hline \multicolumn{2}{|l|}{ Internet usage rate } \\
\hline Several days a week & 6.3 \\
\hline Several days a month & 2.1 \\
\hline Everyday & 91.6 \\
\hline \multicolumn{2}{|c|}{ Participants relationship to the business } \\
\hline Owner & 27.1 \\
\hline Representative & 18.8 \\
\hline Employee & 54.2 \\
\hline \multicolumn{2}{|l|}{ Business age in years } \\
\hline $0-5$ & 16.7 \\
\hline $6-10$ & 16.7 \\
\hline $11-20$ & 10.4 \\
\hline Over 20 & 56.3 \\
\hline \multicolumn{2}{|c|}{ Number of employees in business } \\
\hline $0-10$ & 18.8 \\
\hline $11-50$ & 8.3 \\
\hline $51-250$ & 4.2 \\
\hline More than 250 & 68.8 \\
\hline \multicolumn{2}{|c|}{ Annual net profit in SAR $(1 \mathrm{GBP} \approx 5.7) \mathrm{SAR}$} \\
\hline $0-60000$ & 10.4 \\
\hline $61000-12000$ & 4.2 \\
\hline $121000-180000$ & 2.1 \\
\hline $181000-240000$ & 4.2 \\
\hline More than 240000 & 35.4 \\
\hline Unknown & 43.8 \\
\hline \multicolumn{2}{|l|}{ Business field } \\
\hline Constructing and building & 14.6 \\
\hline Restaurants & 2.1 \\
\hline Food supply and grocery & 4.2 \\
\hline Cars trade (sale and lease) & 12.5 \\
\hline Communication & 6.3 \\
\hline Health and medical supply & 14.6 \\
\hline Other & 45.8 \\
\hline
\end{tabular}

\section{B. Measures of central tendency}

A measure of central tendency is a single value that attempts to describe a set of data. We define measures of central tendency to find some central values around which the data tend cluster or concentrate [15]. The mean is the most popular measure of central tendency and it can be computed by the following formula where $\bar{x}$ denotes to the mean, $n$ is the number of values and $X n$ represents the values [16]:

$$
\bar{x}=\frac{(X 1+X 2+\ldots .+X n)}{n}
$$

The median is the middle score of the data set values that have been arranged in order of magnitude. Since 
Likert response measures were used in this research, clarifications of the instrument scales will be presented in the following section. These clarifications helped us to choose the appropriate central tendency measures in the descriptive statistics and analysis.

\section{Likert-Type vs Likert Scale}

Clason and Dormody identified the Likert-Type items as single questions that use some aspect of Likert responses. Whereas, Likert Scale is composed of multiple Likert-Type items that are combined into one single composite score/variable during the data analysis process. The composite score that combined multiple items represents a quantitative measure for the intended aspect that needs to be measured [17]. LikertType item categorized as an ordinal measurement scale and therefore, the recommended descriptive statistics are mode or median for central tendency and Inter-Quartile range (IQR) for variability. On the other hand, Likert Scale is categorized as interval measurement scale since it is represented as a composite score that is combined multiple items (either the sum or the mean of the combined items). Therefore, the recommended descriptive statistics are mean for central tendency and standard deviation (S.D.) for variability [18].

\section{Descriptive analysis of data}

In this section, the collected data will be analysed in relation to EGAUM constructs [5]. The participants from business sector were asked to describe several characteristics including their attitude, behaviour and opinion towards adopting and utilizing the e-Government systems. Such characteristics were examined through number of statements using different Likert Scales. Likert Scale scores were also calculated in order to interpret the participants' responses.

Perceived Benefits (PB) was measured with 7 items in order to indicate its influence on the respondents' adoption and utilization of e-Government systems. The participants were asked questions to determine their perception degree on several main benefits that they can gain from using e-Government services for their businesses. The perceived benefits that were measured included the speed of processing e-Transactions over the traditional ways, ensuring the equality of processing business entities' transactions and providing investment opportunities for the business sector. They also measured the respondents' perception of the ability of e-Government to save time, cost and effort. All the items in this factor were measured using 5-points Likert scale ranging from 'Strongly agree' to 'Strongly disagree'.

In respect to the perceived benefits influence, the results showed that the vast majority of the participants $97 \%$ believed that e-Government would enable them to perform their business transactions quicker than traditional ways. Moreover, around $95 \%$ of them believed that using e-Government services would save time, cost and effort. With regard to the
TABLE 3: The result of PB factor

\begin{tabular}{ccccc}
\hline Factor & \# of item & Mean & S.D. & $\begin{array}{c}\text { result } \\
\text { interpretation }\end{array}$ \\
\hline PB & 7 & 1.37 & 0.49 & Very influential
\end{tabular}

benefits that they can gain for their businesses' entities, 89\% of the respondents thought that using e-Government systems would minimize legal and regulatory violations that might occur from their businesses and $89 \%$ of them believed that using e-Government would help their businesses to comply with the governmental requirements.

The results also showed that the overwhelming majority $(91 \%)$ of the respondents believed that using e-Government services would ensure equality in the dealing between governmental agencies and business entities. Furthermore, over $80 \%$ of the respondents thought that e-Government would increase the investment opportunities in business sector. It is clear from the results that the perception of the possible gained benefits from using e-Government was relatively high amongst users in the business sector. Table 3 presents the total score of this factor' items.

Perceived Benefits was found as a very influential factor with a total score of 1.37 i.e. PB has a strong impact on the adoption and utilization of users from business sector when using e-Government systems. The results suggest that the intention to use e-Government services is very likely to increase if users from business sector perceive the e-Services to be beneficial for their businesses. This indicates that to get business owners and business representatives to adopt and use e-Government services, these services must be genuinely useful for their business. They should be implemented efficiently and effectively in order to meet the needs of this category of stakeholders. These findings are in accordance with results reported in the literature, for example, [19] and [20] that have been conducted in the US. The findings also in accordance with a study conducted in Kuwait which is a close neighbour country to Saudi Arabia that have similar nature and culture. [21].

Socio-Cultural (SC) was measured with 5 items using 5points Likert scale. SC factor was concern with the influence of others, including colleagues and other business entities, on the intention to use e-Government. It also concerned with the influence of cultural norms, believes and behaviour patterns in Saudi Arabia on the adoption and use of e-Government services. For example, the respondents were asked to determine whether they feel that dealing with government agencies regarding their businesses' transactions should be real and tangible i.e. using papers not electronic means. The results showed that $70 \%$ of them disagreed with this item. Moreover, about three quarters of the respondents $(75 \%)$ believed that e-Government would reduce the use of the interpersonal relationships (wasta) when processing business entities' transactions. This indicates a high perception about 
TABLE 4: The result of SC factor

\begin{tabular}{lcccc}
\hline Factor & \# of item & Mean & S.D. & $\begin{array}{c}\text { result } \\
\text { interpretation }\end{array}$ \\
\hline SC & 5 & 2.44 & 0.79 & Influential
\end{tabular}

the ability of e-Government systems to eliminate or reduce this behaviour pattern. Furthermore, the results also showed that $81 \%$ of the respondents would be encouraged to use e-Government services for their businesses transactions if they know that other business entities use them. This indicates that the social influence is relatively high in terms of using e-Government services (see Table 4 for total score of SC).

The influence of some social aspects involved in this study, such as the influence of other, was not supported in other research such as a study conducted by AlAwadi and Morris [22]. However, the findings related to the influence of cultural aspects were in consistent with those reported in AlAwadi and Morris's study.

In respect to the Awareness (AW) factor, the respondents were asked two groups of questions with two different 5points Likert scales. The first group (AW p1) was to evaluate the participants' awareness and measure the influence of the Awareness factor on their adoption and utilisation of e-Government systems. The 5-points Likert scale in this group was ranging from 'Strongly agree' to 'Strongly disagree'. The second group of questions was to measure the influence of several awareness methods that can affect the participants' awareness which in turn affect their willingness to accept and use e-Government services for their businesses' transactions. The 5-points scale used in this group was ranging from 'Very influential' to 'Very uninfluential'.

The results of the first group revealed that around $64 \%$ of the participants felt that they had good knowledge about eGovernment potentials and services while $6 \%$ did not feel that. Moreover, $29 \%$ gave neutral or do not know responses. The reason of having slightly high percentage of 'Neutral or do not know' responses is likely because some participants did not know much about e-Government potentials and services due to lack of advertisements and awareness campaigns, so they did not feel that they had good knowledge about such benefits and services. Moreover, the results of the first group also showed that the majority of the respondents (89\%) agreed with the item "Offering workshops and visual presentation about potentials and services provided for business sector would encourage me to attend to know more about e-Government". This indicates that such awareness campaigns would increase the adoption

TABLE 5: The result of AW factor

\begin{tabular}{ccccc}
\hline Factor & \# of item & Mean & S.D. & $\begin{array}{c}\text { result } \\
\text { interpretation }\end{array}$ \\
\hline AW p1 & 3 & 2.14 & 0.78 & Influential \\
AW p2 & 6 & 1.97 & 0.97 & Influential
\end{tabular}

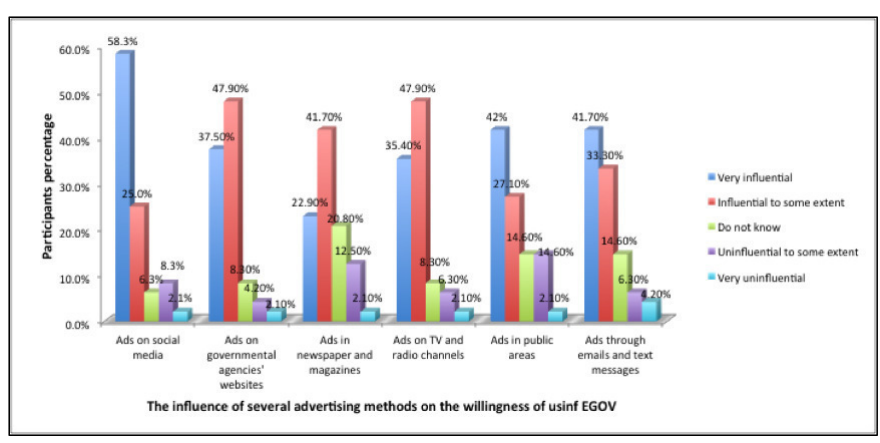

Fig. 1: The result of AW p2

and usage level of the users from business sector. Table 5 presents the total score of AW p1. In the second part (AW p2), the most dominant advertising methods were introduced to the participants to determine the influence degree of such methods on their willingness to use e-Government services for their businesses' transactions. Fig 1 shows the introduced advertising methods and their influence on the participants' willingness to use e-Government services.

It can be seen that $58 \%$ of the respondents reported that ads on social media significantly influence their willingness to use e-Government for their businesses' transactions. Albayari stated that social media revolutionized the business sector in Saudi Arabia since it creates sufficient ways to communicate with customers [23]. This means that most of business entities have accounts in social media networks and also new businesses are expected to follow the same trend of using social media. The result of this study and the status of social media spread in business sector in Saudi provide government with an excellent way of marketing e-Government services and increase the awareness about their benefits and potentials. Furthermore, $42 \%$ of the respondents reported that ads on public areas, such as billboards and banners, are very influential way that would increase their willingness to use e-Government services for their business. Advertising through emails and text messages comes third in terms of a very influential method with a percentage of $41 \%$.

The higher three percentages of advertising methods that were reported as influential to some extent were ads on governmental agencies' websites (47.9\%), ads on TV and radio channels $(47.9 \%)$ and ads in newspaper and magazines $(41.7 \%)$. It is likely that most of the participants are not usually exposed to such advertising; hence, they were reported as 'Influential to some extent' methods. Since the majority of the participating businesses were large companies, they usually linked to some governmental agencies electronically and thus, respondents did not see many ads on the agencies' websites. Being linked electronically means being viewed with the system directly not through website interfaces. Moreover, most of the respondents were employees in the participating businesses (70\%) and it is likely that they do not usually have time to watch $\mathrm{TV}$, listen to radio, read 
newspaper and magazines. Thus, they reported these methods as influential methods that affect their willingness to some extent. Participants who reported uninfluetial responses (either 'Very uninfluetial' or 'Unifluetial to some extent') were relatively low in general.

The overall score for Awareness p2 was 1.97 indicating that the proposed advertising methods, which is part of the Awareness factor, influence to some extent the willingness to use e-Government systems for business entities' transactions. Furthermore, the overall findings of part 1 and 2 indicate the need for sufficient and efficient awareness and also indicate its influence on the adoption and usage level. These findings are similar to those revealed by AlAwadi [22], Alshihi [24] and Davies [25].

Functional Quality of Service (FQS) has also been divided into two parts. The first part (FQS p1) comprised 4 items that measure the influence of the quality of service on the adoption and utilisation of e-Government systems but from functional aspect that concern with the e-Service itself. This part measures how the respondents feel about the general quality of provided e-Services through e-Government, how using e-Government would enhance the quality of their businesses' activities, what is the influence of important external factors (such as post and payment services) on the quality of services provided by e-Government. The items in this part were measured with 5-point Likert scale ranging from 'Strongly agree' to 'Strongly disagree'.

The results of the first part revealed that $48 \%$ of the respondents felt that e-Government services provided to business sector are high quality services. A slightly high proportion of respondents was neutral or did not know whether such e-Services are high quality and they represented $35 \%$. When investigating neutral responses percentage, it was found that over $70 \%$ of them were employees. Employees who are responsible for performing e-Services in companies in Saudi Arabia usually are divided into different groups. Each group is responsible to deal with one governmental agency in terms of performing e-Transactions. Therefore, it is very likely that they cannot judge the e-Government services in general as they might be dealing with certain amount of e-Transactions. Moreover, The vast majority of the respondents $(85 \%)$ agreed on that using e-Government systems would enhance the quality of their business activities.

The influence of significant external factors that are related to the functional quality of service such as the Saudi post mail services and payment options were also measured. Around $43 \%$ of the respondents agreed with that the Saudi post mail services are fast and reliable whereas $27 \%$ disagreed and $29 \%$ responded with 'Neutral or do not know' answers. Although the majority showed an agreement, the other proportions (disagree and neutral proportions) were relatively high. Those two percentages can be interpreted as that the Saudi post mail
TABLE 6: The result of FQS factor

\begin{tabular}{ccccc}
\hline Factor & \# of item & Mean & S.D. & $\begin{array}{c}\text { result } \\
\text { interpretation }\end{array}$ \\
\hline FQS p1 & 4 & 2.21 & 0.66 & Influential \\
FQS p2 & 6 & 1.74 & 0.95 & Very influential
\end{tabular}

provides insufficient services for correspondence between business members and government agencies. Furthermore, it is likely that many business entities do not benefit from the Saudi post mail due to its limited services. With regards to the payment options, over three quarters $(79 \%)$ of the respondents agreed with the sufficiency of SADAD system, which is the only payment method for governmental transactions in Saudi Arabia, whereas only $10 \%$ disagreed. SADAD is an intermediary system between banks and billers where it allows customers to pay for services. Although there are not many options for online payments methods in Saudi Arabia, the results showed high satisfaction level of the current payment system. Table 6 shows the total score of FQS p1.

The second part of Functional Quality of Service factor (FQS p2) comprised 6 items. They measured to what extent certain features, that are related to the functional quality aspect, are important to the respondents when using e-Government services for their businesses' e-Transactions. The measured features include the ability to track transactions online, the ability to view the history of the performed e-Transactions, the ability to appeal electronically, providing effective customers services and the ability to rate the quality of the provided e-Services.

The results of FQS p2 revealed that the ability to track governmental transactions online was very important to three quarters of the respondents $(75 \%)$. The same percentage also reported that the ability to appeal online in case of transaction rejection was highly important to them. The vast majority of the respondents (80\%) agreed on that the ability to view the history of all performed transactions online is of high importance degree. Over $70 \%$ of the respondents considered the feature of communicating with them regarding to the status of their businesses' transactions as of high importance. One of the functional features that is related to the quality of the provided services is providing customer care services. The participants were asked to determine the importance degree of providing such services that are dedicated only to serve customers from business sector with using e-Government services. The majority of participants $(72 \%)$ reported high importance degree of the existence of such services.

The high importance degrees that were reported to most of the proposed functional features revealed the positive influence of providing these features when implementing e-Government services for business sector. Such functional features reflect high quality of the implemented e-Services and it is very likely that they would increase the adoption 
TABLE 7: The result of PE factor

\begin{tabular}{cccc}
\hline Item & Median & IQR & $\begin{array}{c}\text { result } \\
\text { interpretation }\end{array}$ \\
\hline PE1 & 2 & 1,2 & Influential \\
PE2 & 1 & 1,1 & Very influential \\
PE3 & 1 & 1,3 & Very influential
\end{tabular}

and usage level (see Table 6 for total score of FQS).

Previous Experience (PE) factor comprised three items,namely, PE1, PE2 and PE3 that measured the influence of Previous Experience on the intention to adopt and use e-Government services provided to business sector. Each of which had different measurement scale with three possible answers. The answer options of this factor's items were narrowed to three because we would like to gain more accurate results for exploring the impact of previous experience.

The respondents were asked to rate their previous experience of using e-Government services for their businesses' transactions. The results showed that $43 \%$ were fully satisfied, $54 \%$ were satisfied to some extent and only $2 \%$ were not satisfied. Although the percentages of fully satisfied and unsatisfied respondents were good indication of efficiency of the current e-Government services, the high percentage of respondents who were satisfied to some extent was, on the other hand, questionable. Therefore, information about the reasons that made the previous experience of some respondents not fully satisfied has also been collected. The reported reasons included difficulty of using e-Government service, lack of clarity of the requirements and failure to obtain the expected results of using such e-Services.

The participants were also asked to indicate how the previous experience of using e-Government for their business would affect their future use in item PE2. Three quarters of them $(76 \%)$ stated that it will encourage them to use such systems for all their businesses' transactions whereas $8 \%$ stated that it made them hesitant to use such systems again. The high percentage of the encouraged respondents was not necessary an indication of high satisfactory level. It is likely that the need for online governmental service was the main reason of this high percentage of encouraged respondents. The slightly high proportion of respondents who reported that there will be no effect of the previous experience (15\%) support this assumption.

Another item that measure the influence of the previous experiences of using online services was item PE3. It asked the participants who have used non-governmental online transactions for their businesses whether such experience would affect their willingness to use online governmental services. The results showed that over half of the respondents (57\%) answered 'Yes, positively', only 3\% answered 'Yes, negatively' and around $39 \%$ answered 'No effect'. This
TABLE 8: The result of PS factor

\begin{tabular}{lcccc}
\hline Factor & \# of item & Mean & S.D. & $\begin{array}{c}\text { result } \\
\text { interpretation }\end{array}$ \\
\hline PS p1 & 3 & 1.96 & 0.63 & Influential \\
PS p2 & 3 & 1.78 & 0.89 & Very influential
\end{tabular}

indicates that using online transactions and services (not governmental ones such as online banking and online purchasing) is very likely to influence the willingness of using e-Government services and transactions. All the total scores of PE items are presented in table 7.

Perceived Simplicity (PS) factor comprised two groups of items and each group had different measure scale. The first group (PS p1) involved three items and they measure to what extent the perceived simplicity would influence the participants' adoption and utilisation of eGovernment systems. The results of this part revealed that the overwhelming majority of the respondents $(85 \%)$ believed that e-Government services provided to business sector are easy to use. However, over half of them $(68 \%)$ were feeling that using such e-Services requires high level of concentration. This is likely because the lack of instant communication between customers and e-Services providers. In traditional ways, customers can instantly interact with the governmental employees who serve or conduct governmental transactions and thus, governmental employees can inform the customers if there is any mistakes or incomplete information and documents that make the performed transaction unaccepted or rejected. Where in online environment, such communication is limited especially when there is no sufficient online communication method such as online chat with representatives. In this case, customers need more concentration when performing e-Services to avoid rejecting them due to lack of or mistakes in the provided information and documents. Furthermore, the results also showed that if using e-Government services were difficult and complex, $79 \%$ of the respondents would hesitate to use them again. The overall score of 1.96 (see Table 8) indicated that PS factor is likely influence the adoption and utilisation level. In other word, the difficulty and complexity of using e-Government services would negatively influence the willingness of users from business sector to use such e-Services.

In PS p2, the respondents were asked to determine the importance degree of proposed important information related to the simplicity of use. The proposed information involved detailed steps on how to perform e-Services online (item PS4), texts or pictures that clarify the required information and documents (item PS5) and explanation of processing steps of the intended e-Service (item PS6). The proposed information is strongly related to the ease of use and thus, the participants were asked to specify to what extent such information is important to them. Measuring the importance 


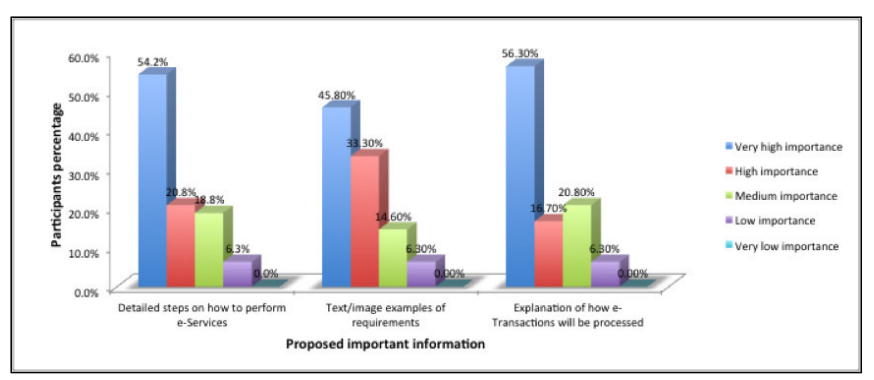

Fig. 2: The result of PS p2

of such information will give an indication on whether the simplicity would influence the adoption and utilisation of e-Services. The results of PS p2 are presented in Fig 2.

It is clear from the figure that almost half of the respondents believed that providing such information is very important to them and they represented 54\% for item PS4, $45 \%$ for item PS5 and 56\% for item PS6. Approximately 33\% reported 'High importance' for providing textlimage examples of the requirements whereas $16 \%$ reported the same degree of importance to providing explanation of the processing steps and 20\% also reported the same degree of importance to providing detailed steps on how to perform e-Services. Generally, clarifying the required information and documents with texts and pictures examples was the most important information as $79 \%$ of the respondents indicated 'Very high' to 'High' importance level. Remarkably, none of the participants believed that such information has very low importance degree. This indicated that all the proposed information had relatively high importance degree to the respondents (see Table 8 for the total score of PS p2) and therefore, it is very likely that providing such information would positively influence their adoption and utilisation of e-Government services.

E-Government services need to be straightforward and simple to use in order to enable all potential users to benefit from such e-Services. This simplicity is emphasised when it comes to providing e-Services to business sector where large number of e-Services and e-Transactions are needed. Other studies such as Carter and Belanger [26] and Phang et al. [27] also found that simplicity and ease of use is a significant factor that influence the intention to use e-Government.

Technical Quality of Service factor was measured with five items and they were divided into two parts measured with 5-poits Likert scale (agreement scale and importance degree scale). The results of the first part revealed that $68 \%$ agreed with that the technical errors such as links not working and server errors would affect negatively their willingness to use such e-Services. This high agreement is expected since the technical aspects in e-Government systems are crucial in terms of quality of service especially when they are visible
TABLE 9: The result of TQS factor

\begin{tabular}{lcccc}
\hline Factor & \# of item & Mean & S.D. & $\begin{array}{c}\text { result } \\
\text { interpretation }\end{array}$ \\
\hline TQS p1 & 2 & 2.40 & 0.96 & Influential \\
TQS p2 & 3 & 1.84 & 0.87 & Influential
\end{tabular}

to the users. Moreover, the majority of the respondents (70\%) agreed with that the interface design and layout of e-Government websites would influence their willingness to use e-Government for their business. It has been found from the results of this part (see Table 9) that the technical aspects are very important in terms of quality of service perception and thus, providing e-Services with high technical quality is fundamental. A high quality of the technical side including the design, structure and layout of e-Government portals is needed for the successful adoption and utilization [28].

TQS part 2 was concern with measuring the importance degree of providing important information that is related to the technical side of e-Services (see Fig 3). Such information is important in terms of quality of service perception but from the technical side. The majority of the respondents reported that providing the proposed information is very important to them when using e-Services for their businesses. Half of the participants $(50 \%)$ reported 'Very high importance' for providing information about the expected time to complete their businesses' e-Transactions, 45\% reported the same importance degree for providing the last update time of e-Services websites and $47 \%$ also reported the same level of importance for providing the last update time of procedures and requirements that their businesses have to comply with. The overall score of 1.84 that is presented in Table 9 indicates that the proposed information had high importance degree for the users from business sector and thus, providing such information would likely increase their usage.

Furthermore, the results of TQS (part 1 and 2) indicates that this factor would influence the adoption and utilisation of users from business sector. They showed that reducing technical errors, enhancing interfaces design and providing information that reflect high technical quality of service would definitely increase the adoption and usage level of

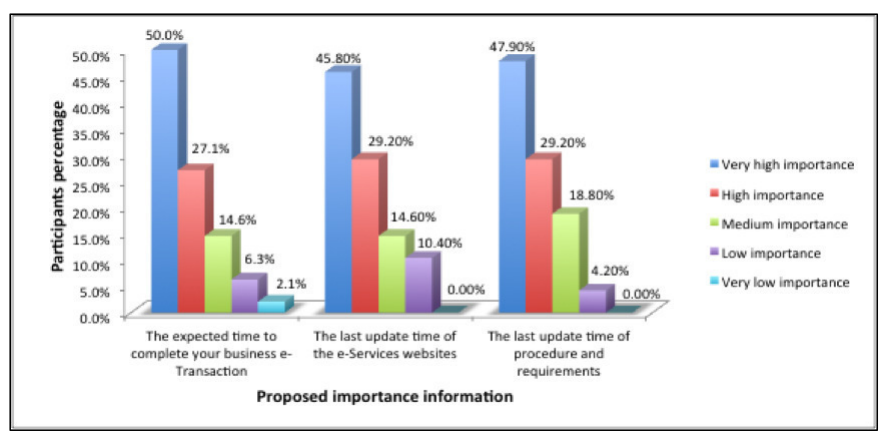

Fig. 3: The result of TQS p2 
TABLE 10: The result of ACC1 factor

\begin{tabular}{lccc}
\hline Item & Median & IQR & $\begin{array}{c}\text { result } \\
\text { interpretation }\end{array}$ \\
\hline ACC1 & 2 & $1,2.5$ & Influential
\end{tabular}

e-Government services provided to business sector. Therefore, paying more attention on technical aspects that appear directly to the users is important.

In terms of Accessibility (ACC) factor, three quarters of the respondents $(75 \%)$ thought that the existence of authorised offices to help them to access and use e-Government services is a good idea. The authorised offices meant to be official agencies that are associated with governmental organisations to provide help to users with accessing e-Government systems, performing e-Transactions and corresponding with governmental organisations on behalf of users. This high percentage is likely because e-Government is still in early stages in Saudi Arabia and also the infrastructure of communications and post mails is in developing phases. Such help method is also useful for users in rural areas where there are no governmental agencies. This method can be introduced at lease in the developing phase of e-Services where many users are likely need help to access and use such e-Services. This result is supported by a study that has been conducted by Alsobhi et al. in Al-Madinah city, which is a large city in Saudi Arabia, to investigate the influence of intermediary agencies on the adoption and usage level. Those agencies were authorised to facilitate communication and coordination between public services providers and customers. The findings of Alsobhi's study showed that intermediaries are an extremely useful channel for improving the adoption and utilisation of e-Government [29]. Table 10 shows the overall score of this item (ACC1).

In the second part of Accessibility factor measurement, the participants were asked to indicate the importance degree of the existence of several features that are related to accessibility. These features are shown in Fig 4. It has been found that having full control of data presence in e-Government systems was highly important to three quarters $(75 \%)$ of the participants. This indicate that users from

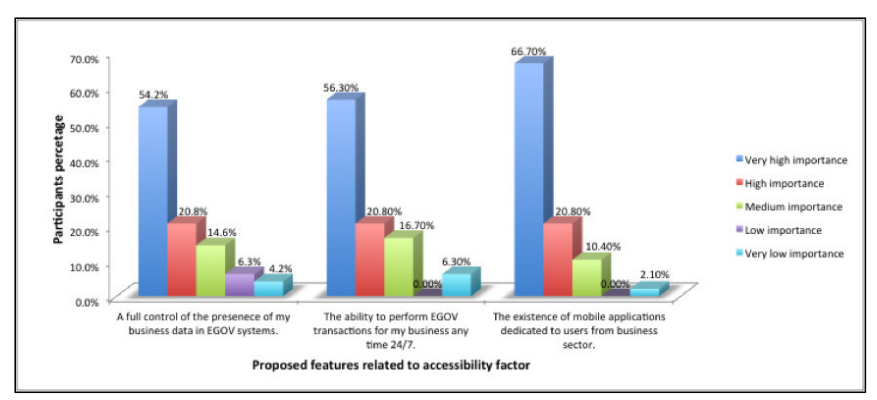

Fig. 4: The result of ACC p2
TABLE 11: The result of ACC p2

\begin{tabular}{lcccc}
\hline Factor & \# of item & Mean & S.D. & $\begin{array}{c}\text { result } \\
\text { interpretation }\end{array}$ \\
\hline ACC p2 & 3 & 1.71 & 0.85 & Very influential
\end{tabular}

business sector prefer to have a full access to their businesses data stored in e-Government systems and also to have full control over it where they can delete it or keep it stored. Moreover, accessing e-Government services provided to business sector at any time ( 24 hour and 7 days) was of high importance to approximately $77 \%$ of the respondents. Since most of the participating business entities (around 70\%) were large companies, it is likely that they have large number of governmental transactions that they need to perform and the participants (just over $80 \%$ were employees) prefer to have flexibility to perform them at any time even out of working hours.

As another accessibility method that can influence the adoption and utilisation of e-Government services, providing e-Services through mobile applications was highly important to the vast majority of the participants with a percentage of $87 \%$. This indicates that the flexibility to access eGovernment systems from anywhere is very important to users from business sector and it is very likely that providing mobile application for this purpose will increase the adoption and utilisation level. Table 11 presents the overall score of ACC part 2 (1.71) which indicates the strong impact of Accessibility on the adoption and usage.

Perceived Trust (PT) factor was measured with nine items using 5-points Likert scale ranging from 'Strongly agree' to 'Strongly disagree'. PT factor concerned with three crucial aspects, namely, trust, security and privacy. Thus, all these aspects were measured with different items. The analysis of this factor revealed that $58 \%$ of the participants agreed with that the Internet is safe to be used to perform governmental e-Transactions for their businesses whereas $27 \%$ disagreed. This indicates high security perception from the respondents towards using the online means for performing e-Government transactions although the proportion of disagreed responses was slightly high. Thus, the result was investigated further and it was found that the education level of $54 \%$ of the respondents who reported an agreement on that the Internet is not safe were secondary school or less. It is likely that the education level had an impact on the security perception when using online governmental services.

The results also indicated a relatively high privacy perception since over half of the respondents $(56 \%)$ would not hesitate to provide sensitive information through eGovernment systems. The same percentage of $56 \%$ also disagreed with a statement stated "Dealing with government agencies electronically online could cause invasion of my business privacy". Furthermore, 64\% of the respondents 
TABLE 12: The result of PT factor

\begin{tabular}{lcccc}
\hline Factor & \# of item & Mean & S.D. & $\begin{array}{c}\text { result } \\
\text { interpretation }\end{array}$ \\
\hline PT & 9 & 2.34 & 0.71 & Influential
\end{tabular}

believed that their business entities' data that are stored in e-Government systems cannot be used by other parties without their permission. Other parties meant to be other governmental organizations or other companies. Moreover, approximately $54 \%$ of the respondents believed that their company's data stored in e-Government systems cannot be misused. These results showed a relatively high trust, security and privacy perception.

The overall score of this factor was 2.34 (see Table 12) and this gives us an indication that Perceived Trust factor is likely influence the adoption and utilisation of e-Government from the perspective of users from business sector. Moreover, the high trust, security and privacy perceptions that have been shown in all items reflect the importance and the impact of trust for both the business owners and employees in business sector.

Regulation and Policies (RP) factor is another factor that was proposed in the utilised model (EGAUM) and it was measured with four items. In these items, the participants were asked to determine the importance degree of providing important information related to the regulations and policies of using e-Government. The proposed information can be seen in Fig 5. It is clear from the figure that all the proposed information was of high importance degree for the majority of the respondents. The graph shows that around $83 \%$ reported that providing e-Version of the regulatory procedures and requirements that their business entities need to comply with was highly important to them. Such procedures and requirements are different according to the business field and activities and they are normally updated regularly by government.

Moreover, providing information security policies was also highly important to over $79 \%$ of the participants. Such policies involve security procedures applied in implementing

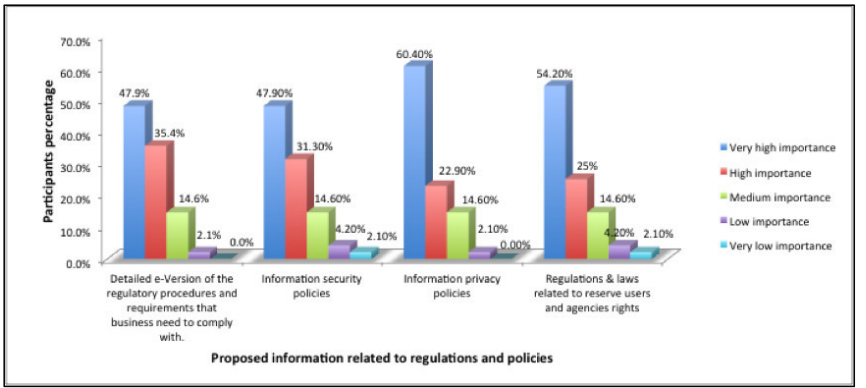

Fig. 5: The result of RP
TABLE 13: The result of RP factor

\begin{tabular}{lcccc}
\hline Factor & \# of item & Mean & S.D. & $\begin{array}{c}\text { result } \\
\text { interpretation }\end{array}$ \\
\hline RP & 4 & 1.71 & 0.79 & Very influential
\end{tabular}

e-Services, security procedures applied in storing users' data and security guidelines that the agencies follow when providing e-Services. Even if the agencies implement high standard policies of information security, users need to see and feel about such security matter. Furthermore, approximately $83 \%$ of the respondents reported high importance degree to the existence of information privacy policies with the highest percentage of 'Very high importance' answer.

Regulations and laws that are related to reserve users' and agencies' rights when using e-Government services were reported as of high important by more than three quarters of the respondents (79\%). Such regulations and laws will protect users' rights when performing and using online e-Services for their business entities. For example, users need to know what they should do when conflict happen with e-Services provider regarding their e-Transactions. Also these regulations and laws will reserve governmental agencies rights when providing e-Services to customers and this include the cases and reasons that give the agency the right to refuse processing an e-Transaction. Remarkably, very low percentages of participants who responded low importance degree to each item.

The results revealed that applying strict, clear and detailed regulations and policies when implementing e-Government systems is very important to the users from business sector. This is likely because users from business sector are cautious and careful about their businesses' transactions. They do not want their business activities to be negatively affected due to lack of knowledge or understanding of regulations and policies especially for large business entities (around 70\% of the participating business entities were large). The total score of 1.71 (see Table 13) indicates that RP is a significant factor that has a strong impact on the adoption and usage of e-Government services provided to business sector.

\section{CONCLUSION}

The adoption and utilisation of e-Government considered to be a challenge, and therefore, an interesting research area is introduced. This paper aimed to identify determinant of potential users' adoption and utilisation of e-Government services from the business sector perspective in Saudi Arabia. This study was based on a comprehensive framework (EGAUM) that proposed fundamental factors related to the adoption and interaction with e-Government services. The utilised model covered substantially all the aspects that have direct and indirect impact on such interaction. The results of the descriptive analysis in this study indicated that all the 
proposed factors have degree of influence. PB, FQS, PE, PS, ACC and RP were found to be significant factors that are very likely influence the adoption and usage level of the users from business sector.

This study is part of an on-going research and thus, the collected data will be analysed with further analysis procedures to explore the correlations between the model's variables. Although there are some limitations in this study such as the majority of male participants and the majority of large participating business firms, this study provides useful insights into the motivations underlying the intentions to adopt and use e-Government services from the business sector perspective in developing countries like Saudi Arabia.

\section{REFERENCES}

[1] E. Ziemba, T. Papaj, and R. Zelazny, A model of success factors for E-Government adoption - the case of Poland. Journal of Computer Information Systems, Vol. 14, Issue 2, pp. 87-100, 2013.

[2] S. AlAwadhi, and A. Morris, Factors influencing the adoption of $e$ government services. Journal of Software, 4(6), pp.584-590, 2009.

[3] M. Kunstelj, T. Jukic, and M. Vintar, Analysing the Demand Side of E-Government: What Can We Learn From Slovenian Users?. Electronic Government Lecture Notes in Computer Science, Vol.4656, pp 305-317, 2007. DOI: 10.1007/978-3-540-74444-3_ 26.

[4] Research and Economic Reports Unit 2015 [Growing rate of private sector in the Kingdom of Saudi Arabia]. Al-Jazirah [Online] Available from: http://www.al-jazirah.com/2015/20150315/ec6.htm (accessed in 28/04/2015) (In Arabic).

[5] S. Alghamdi, and N. Bellof, Towards a Comprehensive Model for E Government Adoption and Utilisation Analysis: The Case of Saudi Arabia. Federated Conference on Computer Science and Information Systems, ACSIS, Vol. 2, pp. 1217-1225, 2014. DOI: 10.15439/2014F146.

[6] J. Raubenheimer, An item selection procedure to maximise scale reliability and validity. SA Journal of Industrial Psychology, 30 (4), 59-64, 2004.

[7] N. Blunch, Introduction to Structural Equation Modelling Using IBM SPSS Statistics and AMOS. Second Edition, SAGE publication Ltd, p.p. 31-50, 2013.

[8] S. McLeod, What is Reliability?, 2013. [Online] Available from: http://www.simplypsychology.org/reliability.html (accessed in 28/01/15).

[9] E. Eucharia, and O. Nnadi, Health Research Design and Methodology. Library of Congress, CRC Press, p.p. 166-168, 1999.

[10] D. Suhr, and M. Shay, Guidelines for Reliability, Confirmatory and Exploratory Factor Analysis. University of Northern Colorado, Cherry Creek Schools, USA, 2008.

[11] D.K. Bhattacharyya, Cross-cultural Management: Texts and Cases. PHI learning private limited, New Delhi, p.p.317-319, 2010.
[12] D. Colton, and R.W. Covert, Designing and Constructing Instruments for Social Research and Evaluation. Jossey-Bass, Wiley Imprint, San Francisco, p.p. 64-74, 2007.

[13] B.R Worthen, W.R. Borg, and K.R. White, Measurement and evaluation in the schools. New York: Longman, 1993.

[14] B. Nevo, Face validity revisited. Journal of Educational Measurement, 22, pp. 287-293, 1985

[15] J.A. Khan, Research Methodology. S.B. Nangia, APH Publishing Corporation, New Delhi, p.p. 135-143, 2008.

[16] Laerd Statistics (n.d.) Measures of Central Tendency. [Online] Available from: https://statistics.laerd.com/statistical-guides/measures-centraltendency-mean-mode-median.php (accessed in 12/04/2015).

[17] D.L. Clason, T.J. Dormody, Analyzing data measured by individual Likert-type items. Journal of Agricultural Education, 35(4), p.p.31- 35, 1994.

[18] H.N. Boone, and D.A. Boone, Analyzing Likert Data. Journal of Extension, vol. 50, No. 2. Article number: 2TOT2. West Virginia University, Morgantown, West Virginia, 2012.

[19] L. Carter, and F. Belanger, Citizen adoption of electronic government initiatives, 37th Hawaii International Conference on System Sciences, Hawaii, 2004.

[20] D.V . Dimitrova and Y .C. Chen, Profiling the adopters of e-government information and services: the influence of psychological characteristics, civic mindedness, and information channels. Social Science Computer Review,(24:2), pp.172-188, 2006.

[21] S. AlAwadhi and A. Morris, The use of the UTAUT model in the adoption of e-government services in Kuwait. 41st Hawaii International Conference on System Sciences, Hawaii, 2008.

[22] S. AlAwadi, and A. Morris, Factors Influencing the Adoption of Egovernment Services. Journal of Software, Vol.4, No.6, pp. 584-590, 2009.

[23] KH. H. Albayari, Social Media Websites Create Revolution in Business Sector, 2011. Alriyadh newspaper. [Online] Available from: http://www.alriyadh.com/674523

[24] H. AlShihi, E-government development and adoption dilemma: Oman case study. 6th International We-B (Working for e-Business) Conference, Victoria University, Melbourne, Australia, 2005.

[25] P . Beynon-Davis, Constructing electronic government: the case of the $U K$ inland revenue. International Journal of Information Management, 25, 3-20, 2005.

[26] L. Carter and F. Belanger, The utilization of e-government services: citizen trust, innovation and acceptance factors. Information Systems Journal, (15:1), pp.5-25, 2005.

[27] C. W. Phang, Y. Li, J. Sutanto and A. Kankanhalli, Senior citizens adoption of e-government: in quest of the antecedents of perceived usefulness. 38th Hawaii International Conference on System Sciences, 2005.

[28] E. Ziemba, T. Papaj, and D. Descours, Assessing the quality of egovernment portals - the Polish experience. Federated Conference on Computer Science and Information Systems, ACSIS. Vol.2, pp.12591267, 2014. DOI: $10.15439 / 2014 \mathrm{~F} 121$

[29] V. Weerakkody, R. El-Haddadeh, F. Al-Sobhi, M.M. Shareef, and Y.K. Dwivedi, Examining the influence of intermediaries in facilitating e-government adoption: An empirical investigation. International Journal of Information Management, 33, p.p. 716-725, 2013. DOI: 10.1016/j.ijinfomgt.2013.05.001 